\title{
Alcohol brands' use of age-restriction controls on Facebook and Instagram in Australia
}

\author{
Hannah Pierce a,b, Abbie-Clare Vidlera, Julia Stafford ${ }^{a}$ and Danica Keric ${ }^{a}$ \\ a Cancer Council Western Australia, Perth \\ b Corresponding author: hannah.pierce@cancerwa.asn.au
}

\section{Article history}

Publication date: July 2021

Citation: Pierce H, Vidler A-C, Stafford J, Keric D. Alcohol brands' use of agerestriction controls on Facebook and Instagram in Australia. Public Health Res Pract. 2021; Online early publication. https:// doi.org/10.17061/phrp31232109

\section{Key points}

- The industry marketing code requires age-restriction controls to be activated for alcohol advertising on social networking sites to prevent children's access, however $28 \%$ of Instagram and $5 \%$ of Facebook accounts for alcohol brands owned by the nine dominant alcohol companies in Australia did not have controls activated

- Industry self-regulation of alcohol marketing is not preventing children's access to alcohol content on social networking sites, demonstrating the need for a more effective, government-led regulatory approach

\section{Abstract}

Objectives: Since 2017, the self-regulatory alcohol advertising system in Australia has required alcohol marketers to activate age-restriction controls on social networking sites to prevent access to children. With no monitoring mechanisms, the level of compliance with this requirement is unknown. We aimed to identify the extent to which the dominant alcohol companies in Australia have activated age-restriction controls on their official brand accounts on Facebook and Instagram.

Study type: Nonexperimental descriptive study.

Methods: We identified the brands owned by the top three beer, wine and spirit companies by market share in Australia, and located their official Facebook and Instagram accounts. International accounts were used when Australia-specific accounts did not exist. Two researchers independently attempted to access all accounts on a computer by entering the URL into a web browser that was not logged into either platform. We recorded the accessibility and audience size of each account.

Results: For the 195 alcohol brands that were available for sale in Australia through the nine top companies, we identified 153 Facebook accounts (84 Australian, 69 international) and 151 Instagram accounts (77 Australian, 74 international). We found $28 \%$ of Instagram and $5 \%$ of Facebook accounts did not have age-restriction controls activated. Similar proportions of Australian and international accounts on both platforms were not using controls. Only two companies were compliant across all of their accounts.

Conclusions: Compliance with the industry marketing code requirement for age-restriction controls is inconsistent among the largest alcohol companies operating in Australia. The industry-managed regulatory system is not preventing children's access to alcohol content on social networking sites. 


\section{Introduction}

Alcohol use is estimated to be a contributing factor in more than 4000 deaths annually in Australia. ${ }^{1}$ The World Health Organization recommends enforcing comprehensive restrictions on alcohol advertising as a cost-effective intervention to reduce harmful alcohol use. ${ }^{2}$ It has been established there is a causal relationship between exposure to alcohol advertising and drinking among young people. ${ }^{3}$

Digital advertising has presented new opportunities for alcohol marketers to expand their reach, including through social networking sites. Digital advertising provides benefits to marketers that don't exist in traditional media, such as the ability to collect and use data and algorithms to precisely target consumers, and retail and distribution plugins that take users directly through to online stores. ${ }^{4}$ Rather than simply exposing people to a brand, advertising on social networking sites allows engagement and interaction with marketing activities. ${ }^{5}$ Through the use of marketing tactics such as highly targeted sponsored ads, time-limited video stories and social media influencers, a significant proportion of digital alcohol marketing is 'dark', being only visible to the target audience and not open to public scrutiny. ${ }^{4}$ The lack of transparency as to who is being targeted by alcohol marketers, as well as the extent to which the dominant digital platforms use online tracking to collect consumer data $^{6}$, raises questions about what children and young people may be seeing online. Evidence suggests that engaging with digital alcohol marketing is associated with increased alcohol use and risky drinking behaviour. ${ }^{5}$

In Australia, 97\% of households with children younger than 15 years have internet access ${ }^{7}$, and children as young as 8 years use sites such as YouTube, Facebook, Instagram and Snapchat. ${ }^{8}$ Alcohol marketers have the ability to activate age-restriction controls on social networking sites to limit access to users over the legal purchase age (18 years in Australia). However, research from the UK and US has found that users with a registered birthdate identifying them as under the legal purchase age are able to access alcohol-branded content on Twitter, Instagram and YouTube, despite industry guidelines recommending their exclusion. 9,10 In one Australian study, conducted before the introduction of an industry requirement to activate age-restriction controls, $23 \%$ of participants younger than 18 years self-reported liking or following alcohol brands on social networking sites. ${ }^{11}$

In Australia, alcohol advertising is self-regulated by the alcohol and advertising industries through the Alcohol Beverages Advertising Code (ABAC) Scheme. Since November 2017, the ABAC Responsible Alcohol Marketing Code has required alcohol marketers to use age-restriction controls where available to exclude audiences younger than 18 years. ${ }^{12}$ As the ABAC Scheme has no compliance monitoring mechanisms ${ }^{13}$, it is unknown if alcohol companies are using available controls to restrict access. Complaints have been made to the ABAC Scheme about alcohol companies failing to activate age-restriction controls on social networking sites, suggesting that at least some alcohol marketers are not complying with the self-regulatory code. ${ }^{14}$ In this study, we aimed to identify the extent to which alcohol companies in Australia are complying with the ABAC Scheme's requirement to activate age-restriction controls on Facebook and Instagram.

\section{Methods}

\section{Alcohol brands}

We identified the top three beer, wine and spirit companies by market share in Australia according to industry market research reports (companies listed in Table 2). ${ }^{15,16,17}$ At the time of analysis, the companies accounted for more than $76 \%$ of the beer market, $21 \%$ of the wine market and almost $50 \%$ of the spirit market, and are all signatories to the ABAC Scheme. Using official company websites, we identified the alcohol brands owned or distributed by the nine companies. We then searched for each brand on alcohol retailer websites to ensure their availability in Australia. Brands unavailable for purchase in Australia were excluded from the analysis.

\section{Instagram and Facebook accounts}

We selected Facebook and Instagram for this study as: 1) Facebook remains the most widely used social networking site in Australia, and Instagram is a Facebook subsidiary ${ }^{18}$; 2) Facebook is the second-largest online advertising platform in Australia, accounting for $28 \%$ of online advertising expenditure ${ }^{6}$; 3 ) both platforms have age-restriction controls available; and 4) the Facebook advertising policy, which applies to both Facebook and Instagram, requires alcohol ads comply with all applicable industry codes. ${ }^{19}$

We searched alcohol brand websites and Facebook and Instagram for the existence of official brand accounts on both platforms. Accounts were considered to be official if they included a link to the brand's website, could be accessed from the brand's website, or had a Facebook or Instagram verification badge ('blue tick') identifying it as authentic. We included Australiaspecific brand accounts where they existed; otherwise an international account that met the criteria for being considered official was used. The URL to each Facebook and Instagram account, audience size, and geographical location (Australian or international) was recorded.

\section{Assessment of age-restriction controls}

When activated, age-restriction controls on Facebook and Instagram accounts prevent a user who is either i) logged in with a profile that is registered as being under the age of 18 or ii) not logged in to the platform, from accessing, 
following, or viewing the content of the account. In these situations, the user is asked to log in to continue, or told the page is unavailable or for those older than 18 years only. For examples of an alcohol brand Facebook and Instagram account with age-restriction controls activated, see the supplementary file available from: figshare.com/ articles/figure/Example_of_an_alcohol_brand_Facebook_ and_Instagram_account_with_age_restriction_controls_ activated/14825733.

We tested the presence of age-restriction controls by attempting to access all the Facebook and Instagram accounts on a computer by entering the URL into a web browser that was not logged into either platform. This prevented the platforms from recognising if the user was older than 18 years. A researcher visited each of the alcohol brand accounts between 6 and 10 November 2020 and recorded whether the accounts had age-restriction controls in place. Age-restriction controls were considered to be absent if the account had visible content. A second researcher confirmed the accessibility of each account on 11 November 2020. We discussed the one discrepancy in the results and the first researcher checked the account again to resolve the discrepancy.

\section{Results}

We identified 210 alcohol brands owned or distributed by the nine companies, of which 195 brands were available for sale in Australia. For the 195 brands, we identified 153 official Facebook accounts (84 Australian, 69 international) and 151 official Instagram accounts (77 Australian, 74 international). The cumulative number of followers of the Facebook and Instagram accounts were 138558788 and 4860187 respectively. The number of followers for the Facebook accounts with age-restriction controls activated ranged between 212 and 24490738 (median 70 148), while followers of Facebook accounts with no age-restriction controls activated ranged between 207 and 4302 (median 881). The number of followers for the Instagram accounts with age-restriction controls ranged between 170 and 613000 (median 6859), while followers of Instagram accounts with no age-restriction controls activated ranged between 260 and 134000 (median 2519).

Age-restriction controls were absent for 43 (28\%) of the Instagram accounts and eight (5\%) of the Facebook accounts. Similar proportions of Australian and international accounts were found to not have activated controls on Facebook ( $6 \%$ and $4 \%$ respectively) and Instagram (31\% and 26\%).

For Instagram, accounts of spirit brands were proportionally the most non-compliant with age-restriction controls (32\%), followed by wine brands (31\%) and beer brands (21\%; see Table 1). For Facebook, accounts of wine brands were proportionally the most non-compliant with age-restriction controls (14\%), followed by spirit brands (3\%) (see Table 1).

Coca-Cola Amatil $(n=17)$, Treasury Wine Estates $(n=7)$, and Casella Wines $(n=6)$ were the alcohol companies with the largest number of Instagram accounts without age-restriction controls (see Table 2). Of the three beer companies, Carlton \& United Breweries ( $n=5)$ had the largest number of Instagram accounts without age-restriction controls. Only one wine company (Pernod Ricard Australia) and one spirit company (Diageo Australia) had activated age-restriction controls on all their Facebook and Instagram accounts.

Table 1. Number of Facebook and Instagram accounts of beer, wine and spirit brands operating in Australia with age-restriction controls activated, and the cumulative number of followers

\begin{tabular}{|c|c|c|c|c|}
\hline & \multicolumn{2}{|r|}{ Age-restriction controls } & \multicolumn{2}{|c|}{ No age-restriction controls } \\
\hline & $n(\%)$ & Cumulative number of followers & $n(\%)$ & Cumulative number of followers \\
\hline \multicolumn{5}{|c|}{ Beer brands } \\
\hline Facebook & $42(100)$ & 77490005 & $0(0)$ & 0 \\
\hline Instagram & $34(79)$ & 840582 & $9(21)$ & 85661 \\
\hline \multicolumn{5}{|c|}{ Wine brands } \\
\hline Facebook & $38(86)$ & 4883806 & $6(14)$ & 8384 \\
\hline Instagram & $29(69)$ & 399452 & $13(31)$ & 37149 \\
\hline \multicolumn{5}{|c|}{ Spirit brands } \\
\hline Facebook & $65(97)$ & 56173566 & $2(3)$ & 3027 \\
\hline Instagram & $45(68)$ & 3115016 & $21(32)$ & 382327 \\
\hline \multicolumn{5}{|l|}{ Total } \\
\hline Facebook & $145(95)$ & 138547377 & $8(5)$ & 11411 \\
\hline Instagram & $108(72)$ & 4355050 & $43(28)$ & 505137 \\
\hline
\end{tabular}


Table 2. Number of Facebook and Instagram accounts of beer, wine and spirit brands by alcohol company with age-restriction controls activated

\begin{tabular}{lccc}
\hline Company & Platform & $\begin{array}{c}\text { Age- } \\
\text { restriction } \\
\text { controls } n(\%)\end{array}$ & $\begin{array}{c}\text { No age- } \\
\text { restriction } \\
\text { controls } n(\%)\end{array}$ \\
\hline $\begin{array}{l}\text { Beer brands } \\
\text { Carlton }\end{array}$ & Facebook & $18(100)$ & $0(0)$ \\
$\begin{array}{l}\text { B United } \\
\text { Breweries }\end{array}$ & Instagram & $14(74)$ & $5(26)$ \\
Lion & Facebook & $17(100)$ & $0(0)$ \\
Coopers & Instagram & $15(88)$ & $2(12)$ \\
Brewery & Facebook & $7(100)$ & $0(0)$ \\
Wine brands & Instagram & $5(71)$ & $2(29)$ \\
Pernod Ricard & Facebook & $9(100)$ & $0(0)$ \\
Australia & Instagram & $9(100)$ & $0(0)$ \\
Treasury Wine & Facebook & $23(82)$ & $5(18)$ \\
Estates & Instagram & $20(74)$ & $7(26)$ \\
Casella Wines & Facebook & $6(86)$ & $1(14)$ \\
& Instagram & $0(0)$ & $6(100)$ \\
\hline Spirit brands & & & \\
Diageo & Facebook & $33(100)$ & $0(0)$ \\
Australia & Instagram & $29(100)$ & $0(0)$ \\
Coca-Cola & Facebook & $25(96)$ & $1(4)$ \\
Amatil & Instagram & $12(41)$ & $17(59)$ \\
Asahi & Facebook & $7(88)$ & $1(13)$ \\
Beverages & Instagram & $4(50)$ & $4(50)$ \\
\hline & & &
\end{tabular}

\section{Discussion}

To our knowledge, this is the first study that has examined the use of age-restriction controls by alcohol companies on Facebook and Instagram in Australia. We found that despite the ABAC Scheme requiring the use of agerestriction controls on alcohol brand accounts on social networking sites, $28 \%$ of Instagram and $5 \%$ of Facebook accounts in our study were accessible to people younger than 18 years. These findings are in line with earlier studies from the UK and US that found while alcohol brand accounts on Facebook had age-restriction controls activated, alcohol-branded content on Twitter, Instagram and YouTube was largely accessible to underage users. ${ }^{9,10}$ Our findings also build on the Australian research that reported that prior to the introduction of the ABAC Scheme's requirement to activate age-restriction controls, people younger than 18 years were engaging with alcohol marketing on social networking sites. ${ }^{11}$

The primary strengths of this study were the large sample of alcohol brands, and the straightforward monitoring procedure that can be easily replicated by researchers and practitioners in jurisdictions outside Australia, as well as those working to address marketing regulation of other harmful commodities, such as junk food or gambling. A limitation of the study was our inability to ascertain if the Facebook and Instagram accounts without age-restriction controls activated were for alcohol brands that appeal to young people. We are unaware of research indicating which alcohol brands are popular among young people in Australia, and this may be a potential topic for future research. It is also unknown if the accounts without age-restriction controls activated have followers younger than 18 years, as this information is not made publicly available by Facebook or Instagram.

The level of non-compliance on Instagram is of particular concern. Given the Facebook advertising policy applies to both Facebook and Instagram, it is unclear why we found a higher number of accounts on Instagram without age-restriction controls activated compared with Facebook. While there was a larger audience size among compliant accounts, the 43 alcohol brand accounts on Instagram with no age-restriction controls in place had more than half a million followers in total. All nine companies included in our study have significant market share and are signatories to the ABAC Scheme. The requirement to activate age-restriction controls had been in place for 3 years before our data collection. It would be reasonable to assume that the companies are aware of their obligations under the ABAC Responsible Alcohol Marketing Code.

The results highlight that the ABAC Scheme is not preventing children from accessing alcohol-related content online, and add to the Australian body of research concluding that the ABAC Scheme is ineffective at preventing vulnerable populations, including children, from exposure to alcohol advertising. ${ }^{13,20}$ The lack of monitoring mechanisms or sanctions to ensure compliance have previously been identified as weaknesses of the ABAC Scheme and may be one reason for the level of non-compliance found in our analysis.

It could be argued that digital platforms such as Facebook and Instagram could play a role in implementing restrictions on digital alcohol marketing through stronger internal policies. However, even full compliance with a requirement to activate age-restriction controls would not prevent underage access to social networking sites. The ABAC Scheme itself notes the controls rely on users registering with their correct date of birth, and adults not sharing devices with children. ${ }^{21}$ It is unlikely that Facebook and Instagram could adequately address these two issues. Implementing stronger controls on alcohol marketing also presents an inherent conflict of interest for digital platforms given the advertising revenue they receive, raising doubts about how far the platforms would voluntarily go to restrict marketing to help achieve public health objectives.

Finally, there is already a lack of transparency around how digital alcohol marketing works, as well as what 
consumer data is collected and how it is used, with digital platforms reluctant to share this information with the broader public or decision makers. ${ }^{6,22}$ It would be difficult for those outside Facebook and Instagram to verify if any controls suggested by the platforms would indeed effectively regulate digital alcohol marketing. A government-enforced ban on alcohol marketing on social networking sites has been suggested by academics as one regulatory solution ${ }^{22}$, and may be one of the only options that works to reduce children's exposure to alcohol marketing on these platforms. It would, however, be difficult to extend any Australian legislation restricting digital alcohol marketing to those international Facebook and Instagram accounts that are controlled by multinational companies headquartered overseas, despite the accounts being accessible to Australian audiences.

The inclusion of international accounts in our analysis where Australian accounts did not exist was necessary due to the globalisation of the alcohol industry. Digital marketing may not be region specific for brands owned by multinational companies. The recognised weaknesses in the ABAC Scheme support the need for regulatory action by the Australian Government ${ }^{13,20}$, but this area of marketing may require global cooperation. A legislated regulatory system for alcohol marketing at a national level would be strengthened by a global approach to digital alcohol advertising regulation.

\section{Conclusions}

This study demonstrates that compliance with the ABAC Scheme requirement for age-restriction controls for alcohol advertising on Facebook and Instagram is inconsistent among the largest alcohol companies operating in Australia. The industry-managed regulatory system is not preventing children's access to alcohol content on social networking sites. If the public health objective to reduce children and young people's exposure to alcohol marketing is to be met, government-led regulation of alcohol marketing that includes an effective monitoring system is likely to be needed.

\section{Acknowledgements}

This work was supported by a grant from the Western Australian Health Promotion Foundation (Healthway).

\section{Peer review and provenance}

Externally peer reviewed, not commissioned.

\section{Competing interests}

None declared.

\section{Author contributions}

HP, AV and JS conceived the study. HP, AV and DK carried out the data collection. HP and JS carried out data analysis. All authors contributed to development of the manuscript.

\section{References}

1. Australian Bureau of Statistics. Causes of death, Australia, 2017: deaths due to harmful alcohol consumption in Australia. Canberra: ABS; 2018 [cited 2020 Nov 18]. Available from: www.abs.gov.au/ausstats/ abs@.nsf/Lookup/by\%20Subject/3303.0 2017 Main\%20 Features Deaths\%20due\%20to\%20harmful\%20 alcohol\%20consumption\%20in\%20Australia 4

2. World Health Organization. Tackling NCDs: 'Best buys' and other recommended interventions for the prevention and control of noncommunicable diseases. Geneva: WHO; 2017 [cited 2020 Nov 18]. Available from: www. who.int/publications/i/item/WHO-NMH-NVI-17.9

3. Sargent J, Babor T. The relationship between exposure to alcohol marketing and underage drinking is causal. J Stud Alcohol Drugs. 2020;S19:113-24.

4. Carah N, Brodmerkel S. Alcohol marketing in the era of digital media platforms. J Stud Alcohol Drugs. 2021;81(1):18-27.

5. Noel J, Sammartino C, Rosenthal S. Exposure to digital alcohol marketing and alcohol use: a systematic review. J Stud Alcohol Drugs. 2020;19:57-67.

6. Australian Competition and Consumer Commission. Digital Platforms Services Inquiry interim report. Canberra: ACCC; 2020 [cited 2021 May 19]. Available from: www.accc.gov.au/system/files/ACCC\%20 Digital\%20Platforms\%20Service\%20Inquiry\%20-\%20 September\%202020\%20interim\%20report.pdf

7. Australian Bureau of Statistics. Household use of information technology. Canberra: ABS; 2018 [cited 2020 Nov 18]. Available from: www.abs.gov.au/statistics/ industry/technology-and-innovation/household-useinformation-technology/latest-release

8. Office of the eSafety Commissioner. State of play youth, kids and digital dangers. Canberra: Australian Communications and Media Authority; 2018 [cited 2020 Nov 18]. Available from: www.esafety.gov.au/sites/default/ files/2019-10/State\%20of\%20Play\%20-\%20Youth\%20 kids\%20and\%20digital\%20dangers.pdf

9. Winpenny E, Marteau T, Nolte E. Exposure of children and adolescents to alcohol marketing on social media websites. Alcohol Alcohol. 2013;49:154-59.

10. Barry A, Bates A, Olusanya $O$ et al. Alcohol marketing on Twitter and Instagram: Evidence of directly advertising to youth/adolescents. Alcohol Alcohol. 2016;51:487-92. 
11. Carrotte E, Dietze P, Wright C, Lim M. Who 'likes' alcohol? Young Australians' engagement with alcohol marketing via social media and related alcohol consumption patterns. Aust N Z J Public Health. 2016;40:474-79.

12. The ABAC Scheme. ABAC responsible alcohol marketing code. Canberra: ABAC; 2019 [cited 2020 Nov 18]. Available from: www.abac.org.au/wp-content/ uploads/2019/06/ABAC-Responsible-Alcohol-MarketingCode-21-June-2019.pdf

13. Reeve B. Regulation of alcohol advertising in Australia: does the ABAC Scheme adequately protect young people from marketing of alcoholic beverages? QUT Law Review. 2018;18(1):96-123.

14. The ABAC Scheme. Annual Report 2018. Canberra: ABAC; 2019 [cited 2020 Nov 18]. Available from: www. abac.org.au/wp-content/uploads/2019/03/ABAC-AnnualReport-2018.pdf

15. Oo S. Industry report C1212, Beer manufacturing in Australia. Melbourne: IBISWorld; 2020 May [cited 2020 Nov 18]. Available from: www.ibisworld.com

16. Wu T. Industry Report C1214, Wine production in Australia. Melbourne: IBISWorld; 2020 Apr [cited 2020 Nov 18]. Available from: www.ibisworld.com
17. Reeves M. Industry Report C1213, Spirit manufacturing in Australia. Melbourne: IBISWorld; 2020 Apr [cited 2020 Nov 18]. Available from: www.ibisworld.com

18. Roy Morgan. Facebook on top but Instagram and Pinterest growing fastest. Melbourne: Roy Morgan; 2019 [cited 2020 Nov 18]. Available from: www. roymorgan.com/findings/7979-social-media-trendsmarch-2019-201905170731

19. Facebook. Facebook advertising policies. California: Facebook; c2020 [cited 2020 Nov 18]. Available from: www.facebook.com/policies/ads/restricted_content/ alcohol

20. Pierce H, Stafford J, Pettigrew S, Kameron C, Keric D, Pratt IS. Regulation of alcohol marketing in Australia: a critical review of the Alcohol Beverages Advertising Code Scheme's new Placement Rules. Drug Alcohol Rev. 2019;38:16-24.

21. The ABAC Scheme. Best practice for responsible digital alcohol marketing. Canberra: ABAC; 2019 [cited 2020 Nov 18]. Available from: www.abac.org.au/wp-content/ uploads/2018/09/Best-Practice-for-Responsible-DigitalAlcohol-Marketing-approved-14-9-18.pdf

22. Room R, O'Brien P. Alcohol marketing and social media: a challenge for public health control. Drug Alcohol Rev. 2020;40(3):420-22.

\section{Copyright: (c) (i) () (2)}

(C) 2021 Pierce et al. This article is licensed under the Creative Commons Attribution-NonCommercial-ShareAlike 4.0 International Licence, which allows others to redistribute, adapt and share this work non-commercially provided they attribute the work and any adapted version of it is distributed under the same Creative Commons licence terms. See: www.creativecommons.org/licenses/by-nc-sa/4.0/ 